\title{
Pengaruh Konsentrasi Minyak Serai Wangi (Cymbopogon nardus L.) dan Sari Buah Jeruk Nipis (Citrus aurantifolia Swingle) terhadap Sifat Kimia dan Sensori Permen Keras (Hard Candy) \\ (The Effect of Concentration of Lemongrass Oil (Cymbopogon nardus L.) and Sari Lime Fruit (Citrus aurantifolia Swingle) on the Chemical Properties and Sensory of Hard Candy)
}

\author{
Maya Maulida Zamda ${ }^{1}$, Anshar Patria ${ }^{1}$, Ismail Sulaiman ${ }^{1 *}$ \\ ${ }^{1}$ Program Studi Teknologi Hasil Pertanian, Fakultas Pertanian, Universitas Syiah Kuala
}

\begin{abstract}
Abstrak. Hard candy adalah permen yang memiliki tekstur keras dan penampakan bening serta berkilau (glossy) yang digunakan sebagai penyegar mulut dimana bahan bakunya terdiri dari minyak atsri atau buah. Pada pembuatannya, kombinasi serai wangi-jeruk nipis dipilih karena serai wangi termasuk salah satu minyak atsiri yang mengandung sumber sitronelol. Sedangkan jeruk nipis mengandung sumber asam sitrat dan vitamin C. Penambahan sari jeruk nipis untuk mengurangi rasa sepat dan kelat pada serai wangi. Penelitian ini dilakukan dengan menggunakan Rancangan Acak Lengkap (RAL) dengan pola faktorial yang terdiri atas dua faktor. Faktor pertama adalah konsentrasi serai wangi yang terdiri dari 3 taraf, yaitu $\mathrm{S} 1=0,75 \mathrm{ml}, \mathrm{S} 2=1,5 \mathrm{ml}, \mathrm{S} 3=2,25 \mathrm{ml}$. Faktor kedua adalah konsentrasi sari jeruk nipis yang terdiri dari 3 taraf, yaitu $\mathrm{J} 1=7,5 \mathrm{ml}, \mathrm{J} 2=15 \mathrm{ml}, \mathrm{J} 3=22,5 \mathrm{ml}$. Analisis yang dilakukan terhadap hard candy meliputi kadar air, gula reduksi, dextrose equivalent, organoleptik (hedonik). Pada setiap perlakuan yang berpengaruh sangat nyata dan nyata dilakukan uji lanjut (DMRT). Hasil penelitian menunjukkan bahwa pada kadar air jeruk nipis yaitu semakin tinggi dengan nilai 16,42-24,84, sedangkan kadar air serai wangi semakin tinggi akan semakin rendah dengan nilai $17,19-25,36$. Pada gula reduksi dan dextrose equivalent saling berkaitan yaitu semakin tinggi konsentrasi serai wangi dan jeruk nipis maka semakin tinggi nilai yang dihasilkan. Pada uji organoleptik aroma dan rasa dengan konsentrasi serai wangi semakin tinggi maka nilai yang yang dihasilkan semakin rendah, sedangkan aroma dan rasa dengan konsentrasi jeruk nipis semakin tinggi makan nilai yang dihasilkan semakin tinggi.
\end{abstract}

Kata kunci: Serai wangi, hard candy, jeruk nipis, sukrosa, sirup glukosa.

Abstract. Hard candy is a candy that have a hard texture clear appearance and glossies that is used as a mouth freshener where the raw material consists of essential oils or fruit. This manufacture is combination of lemon grass lime was chosen because lemongrass fragrant is one of the essential oils that containing citronellal. While lime contains a source of citric acid and vitamin C. Adding lemon juice to reduce the feeling of sour and chelation on citronella scented. This study was conducted using a Completely Randomized Design (CRD) with a factorial pattern consisting of two factors. The first factor was concentration of lemongrass consisting of 3 levels, namely S1 $=0.75$ $\mathrm{ml}, \mathrm{S} 2=1.5 \mathrm{ml}, \mathrm{S} 3=2.25 \mathrm{ml}$. The second factor was concentration of lime consisting of 3 levels, namely $\mathrm{J} 1=7.5$ $\mathrm{ml}, \mathrm{J} 2=15 \mathrm{ml}, \mathrm{J} 3=22.5 \mathrm{ml}$. Analysis of hard candy includes water content, reducing sugars, dextrose equivalent, organoleptic (hedonic). Each treatment which has a very real and real significant effect, DMRT was examined. The results showed that the water content of lime was higher with a value of $16.42-24.84$, while the water content of lemongrass fragrant was higher, the lower the value of 17.19 - 25.36. In reducing sugars and dextrose equivalent are interrelated, the higher the concentration of citronella and lemon, the higher the value produced. In the organoleptic test of aroma and taste with the concentration of citronella scent, the higher the value produced was lower, while the aroma and taste with the concentration of lime increased the higher the value produced.

Keywords: lemongrass, hard candy, lime, sucrose, glucose syrup.

Corresponding author: ismail.sulaiman@unsyiah.ac.id

JIM Pertanian - THP, Vol. 4, No. 4, November 2019: 337-344 


\section{PENDAHULUAN}

Serai wangi merupakan tanaman herbal yang tinggi dengan rimbunan daun yang lebat. Tanaman ini berwarna hijau muda, kasar dan memiliki aroma yang sangat kuat dibandingkan dengan serai dapur. Tanaman ini digunakan sebagai meredakan nyeri, mengurangi stress, memperbaiki pencernaan, memperlancar detoksifikasi, dan merawat kulit. Selain serai wangi akan dikombinasikan dengan jeruk nipis untuk meningkatkan aroma, warna, kandungan gizi dan senyawa aktif (Kurniawati, 2010).

Buah jeruk nipis merupakan bahan pangan yang mengandung berbagai manfaat dalam kehidupan sehari-hari. Selain kaya vitamin dan mineral, jeruk nipis juga mengandung zat bioflavonoid yang berguna untuk mencegah terjadinya pendarahan pada pembuluh nadi, kemunduran mental dan fisik, serta mengurangi luka memar. Buah ini sering digunakan sebagai obat tradisional seperti obat batuk, penghilang rasa lelah, panas dalam, anti mabuk dan lain sebagainya. Selain itu jeruk nipis ini juga dimanfaatkan sebagai minuman jus, sirup, perawatan kecantikan dan penyedap bumbu masakan (Sarwono, 2001).

Hard candy adalah jenis permen yang mempunyai tekstur keras dan penampakan bening serta berkilau (glossy). Hard candy dengan kandungan total solid sebanyak 97\% memberikan tekstur yang baik dan umur simpan yang optimal. Secara teknis hard candy digunakan untuk campuran sukrosa dengan sirup glukosa yang dipanaskan tersebut menjadi bening dengan karakteristik tidak ada butiran gula pada permukaaan, kadar airnya sangat rendah (1-3\%) dengan keseimbangan kelembaban relatif dibawah 30 persen, sehingga sangat mudah untuk mengabsorpsi kelembaban dari atmosfer (Faridah et al., 2008).

Berdasarkan pra penelitian pembuatan hard candy serai wangi-jeruk nipis menggunakan sukrosa, sirup glukosa, dan air dengan konsentrasi serai wangi $0,75 \mathrm{ml}$ menghasilkan hard candy dengan rasa yang menyegarkan di tenggorokan. Sedangkan konsentrasi 1,5 $\mathrm{ml}$ dan 2,25 ml menghasilkan rasa yang sepat dan kelat, dari konsentrasi tersebut menjadi acuan yang diteliti dalam penelitian ini.

\section{METODE PENELITIAN}

Penelitian ini dilakukan pada bulan Januari 2019 di Laboratorium Rekayasa Pangan dan Industri, Laboratorium Analisis Pangan dan Hasil Pertanian dan Labratorium Evaluasi Sensoris, Jurusan Teknologi Hasil Pertanian, Fakultas Pertanian Universitas Syiah Kuala, Banda Aceh.

\section{MATERI DAN METODE}

\section{Bahan dan Alat}

Bahan yang digunakan pada penelitian ini adalah minyak serai wangi (yang diperoleh dari daerah Blang Kejeren, Kabupaten Gayo Lues), Jeruk nipis (diperoleh dari pasar rukoh), sirup glukosa merk Bebeko (diperoleh dari pembelian online dengan situs shopee.com dengan nama pelapak my_snackut), sukrosa merk Gulaku (diperoleh dari indomaret Darussalam, Aceh

Pengaruh Konsentrasi Minyak Serai Wangi (Cymbopogon nardus L.) dan Sari Buah Jeruk Nipis (Citrus aurantifolia Swingle) terhadap Sifat Kimia dan Sensori Permen Keras (Hard Candy) (Maya Maulida Zamda, Anshar Patria, Ismail Sulaiman)

Jurnal Ilmiah Mahasiswa Pertanian, Vol. 4, No. 4, November 2019: 337-344 
Besar) dan air. Sedangkan bahan-bahan yang digunakan dalam analisis adalah aquades, $\mathrm{CuSO}_{4}$, garam kalium-natrium tatrat, natrium hidroksida $(\mathrm{NaOH}), \mathrm{Pb}$-asetat, $\left(\mathrm{NH}_{4}\right)_{2} \mathrm{HPO}_{4} 10 \%$, luff schoorl, batu didih, es, KI 20\%, $\mathrm{H}_{2} \mathrm{SO}_{4} 25 \%$, natrium tio sulfat $\mathrm{Na}_{2} \mathrm{~S}_{2} \mathrm{O}_{3} \quad 0,1 \mathrm{~N}$, amonium hidrogen fosfat $\left(\mathrm{NH}_{4}\right)_{2} \mathrm{HPO}_{4} 10 \%$, indikator kanji $0,5 \%$. Alat yang digunakan pada penelitian ini yaitu panci, timbangan digital, pisau, kompor, cetakan, saringan, penangas air, kertas label, gelas ukur, teflon, sendok, wadah, cetakan, plastik pp, aluminium foil, termometer dan alat-alat untuk analisis kimia oven, cawan porselin, buret, kertas saring, labu takar, pipet, labu erlemenyer, pemanas listrik, bak.

\section{Rancangan Penelitian}

Penelitian ini dilakukan dengan menggunakan Rancangan Acak Lengkap (RAL) dengan pola faktorial. Faktornya pertama konsentrasi serai wangi yang terdiri dari 3 taraf yaitu $\mathrm{S} 1=0,75$ $\mathrm{ml}, \mathrm{S} 2=1,5 \mathrm{ml}$ dan $\mathrm{S} 3=2,25 \mathrm{ml}$. Faktor kedua konsentrasi jeruk nipis yang terdiri dari 3 taraf yaitu $\mathrm{J} 1=7,5 \mathrm{ml}, \mathrm{J} 2=15 \mathrm{ml}$ dan $\mathrm{J} 3=22,5 \mathrm{ml}$. Rancangan ini menggunakan dua faktor yang terdiri dari 3 taraf dengan menggunakan 3 kali ulangan sehingga akan di peroleh 27 satuan percobaan. Analisis data mengguanakan IBM SPSS Statistics 22.

\section{Analisis Produk}

Analisis yang akan dilakukan pada penelitian ini meliputi analisis hard candy serai wangi dan buah jeruk nipis. Analisis yang dilakukan terhadap hard candy meliputi kadar air (Andarwulan et al., 2011) analisis gula reduksi (SNI 3547-2-2008), analisis nilai dextrose equivalent (Haryati, 2004) serta uji organoleptik secara hedonik terhadap rasa, aroma, tekstur dan warna permen hard candy. Untuk hard candy perlakuan terbaik dilakukan analisis Dektrose Equivalent dan gula reduksi.

\section{Analisis Data}

Untuk menguji pengaruh dari setiap faktor dan interaksi antar faktor terhadap parameter analisis, dilakukan analisis statistik dengan menggunakan ANOVA (Analysis of varians). Apabila perlakuan yang diberikan menunjukkan pengaruh terhadap parameter yang diuji maka dilakukan uji Duncan.

\section{Prosedur Pembuatan Hard Candy}

Sukrosa di timbang $70 \mathrm{ml}$, sirup glukosa $30 \mathrm{ml}$ dan air $50 \mathrm{ml}$. Kemudian dipanaskan sukrosa dan air pada suhu $110^{\circ} \mathrm{C}$ dengan waktu 10 menit sambil di aduk hingga merata. Setelah campuran merata tambahkan sirup glukosa pada suhu pemanasan $120^{\circ} \mathrm{C}$ dengan waktu 8 menit. Selanjutnya ditambahkan minyak serai wangi $(0,75 \mathrm{ml}, 1,5 \mathrm{ml}, 2,25 \mathrm{ml})$ secara bertahap sambil diaduk hingga rata diikuti dengan menghilangkan gelembung udaranya selama. Tambahkan kembali jeruk nipis $(7,5 \mathrm{ml}, 15 \mathrm{ml}, 22,5 \mathrm{ml})$ secara bertahap sambil diaduk merata selama 3 menit. Kemudian didinginkan hingga suhu $90^{\circ} \mathrm{C}$. Selanjutnya, dituangkan dalam cetekan setelah

Pengaruh Konsentrasi Minyak Serai Wangi (Cymbopogon nardus L.) dan Sari Buah Jeruk Nipis (Citrus aurantifolia Swingle) terhadap Sifat Kimia dan Sensori Permen Keras (Hard Candy) (Maya Maulida Zamda, Anshar Patria, Ismail Sulaiman)

Jurnal Ilmiah Mahasiswa Pertanian, Vol. 4, No. 4, November 2019: 337-344 
dinginkan pada suhu kamar dengan waktu lebih kurang 5 menit hingga padat dan keras. Kemudian dikeluarkan dari cetakan lalu bungkus.

\section{HASIL DAN PEMBAHASAN}

\section{Kadar Air}

Berdasarkan hasil analisis kadar air yang dilakukan pada hard candy serai wangi berkisar antara 16,42 \% - 24,84 \% dengan rata-rata yang didapatkan yaitu 21,05\%. Hasil dari analisis sidik ragam menunjukkan bahwa konsentrasi jeruk nipis $(\mathrm{J})$ berpengaruh nyata $(\mathrm{P}<0,05)$. Pengaruh jeruk nipis pada kadar air dapat dilihat pada Gambar 1.

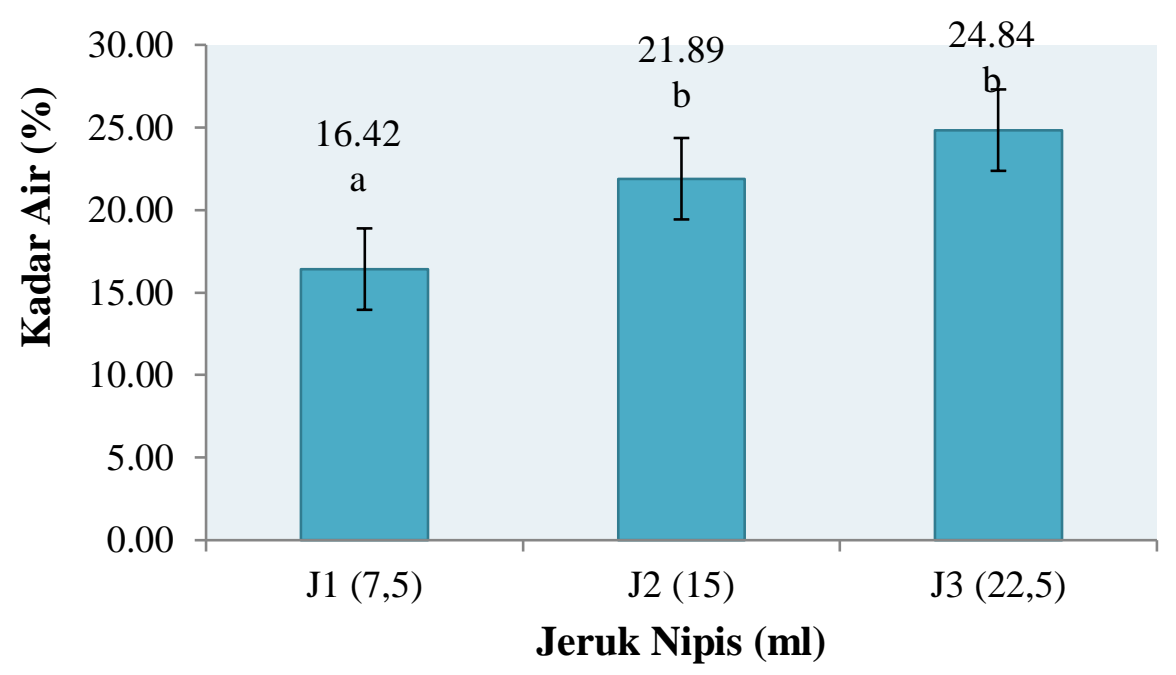

\footnotetext{
Gambar 1. Pengaruh konsentrasi Jeruk nipis (J) terhadap nilai kadar air hard candy (nilai-nilai yang diikuti oleh huruf yang sama menunjukkan perbedaan nyata, DMRT 0,05 taraf $1=12,12$, taraf $2=12,71, \mathrm{KK}=155.902 \%$ ).
}

Gambar 1 menunjukkan bahwa perlakuan jeruk nipis (J1) dengan konsentrasi 7,5 ml menghasilkan kadar air terendah yaitu $16,42 \%$ dan berbeda nyata dengan perlakuan $\mathrm{J} 2$ (15 ml) dan J3 (22,5ml) yang tidak berbeda nyata. Semakin tinggi konsentrasi jeruk nipis yang ditambahkan maka semakin tinggi kadar air yang dihasilkan, karena faktor bahan baku yang digunakan juga sangat mempengaruhi pada suhu pemasakan. Hal ini diduga karena banyaknya kandungan air pada jeruk nipis Menurut Adiono (1985), seni membuat permen dengan daya tahan memuaskan terletak pada pembuatan produk dengan kadar air minimum. Penggunaan suhu $150^{\circ} \mathrm{C}$ diduga cukup tepat untuk menghasilkan permen keras (Hard Candy) dengan kadar air yang cukup tinggi seperti pada penelitian ini.

Pengaruh Konsentrasi Minyak Serai Wangi (Cymbopogon nardus L.) dan Sari Buah Jeruk Nipis (Citrus aurantifolia Swingle) terhadap Sifat Kimia dan Sensori Permen Keras (Hard Candy) (Maya Maulida Zamda, Anshar Patria, Ismail Sulaiman)

Jurnal Ilmiah Mahasiswa Pertanian, Vol. 4, No. 4, November 2019: 337-344 
Berdasarkan hasil analisis kadar air yang dilakukan pada hard candy serai wangi berkisar antara $17,19 \%$ - 25,60 \% dengan rata-rata 20,55\%, dari hasil tersebut nilai yang dihasilkan terlalu tinggi dibandingkan nilai SNI, sedangkan SNI 3547.1:2008 tentang kembang gula keras, kadar air maksimal adalah 3,5\%, maka kadar air yang dihasilkan permen keras (Hard Candy) tidak memenuhi syarat mutu. Hasil dari analisis sidik ragam menunjukkan bahwa konsentrasi jeruk nipis $(\mathrm{J})$ berpengaruh nyata $(\mathrm{P}<0,05)$. Pengaruh konsentrasi serai wangi dapat dilihat pada Gambar 2.

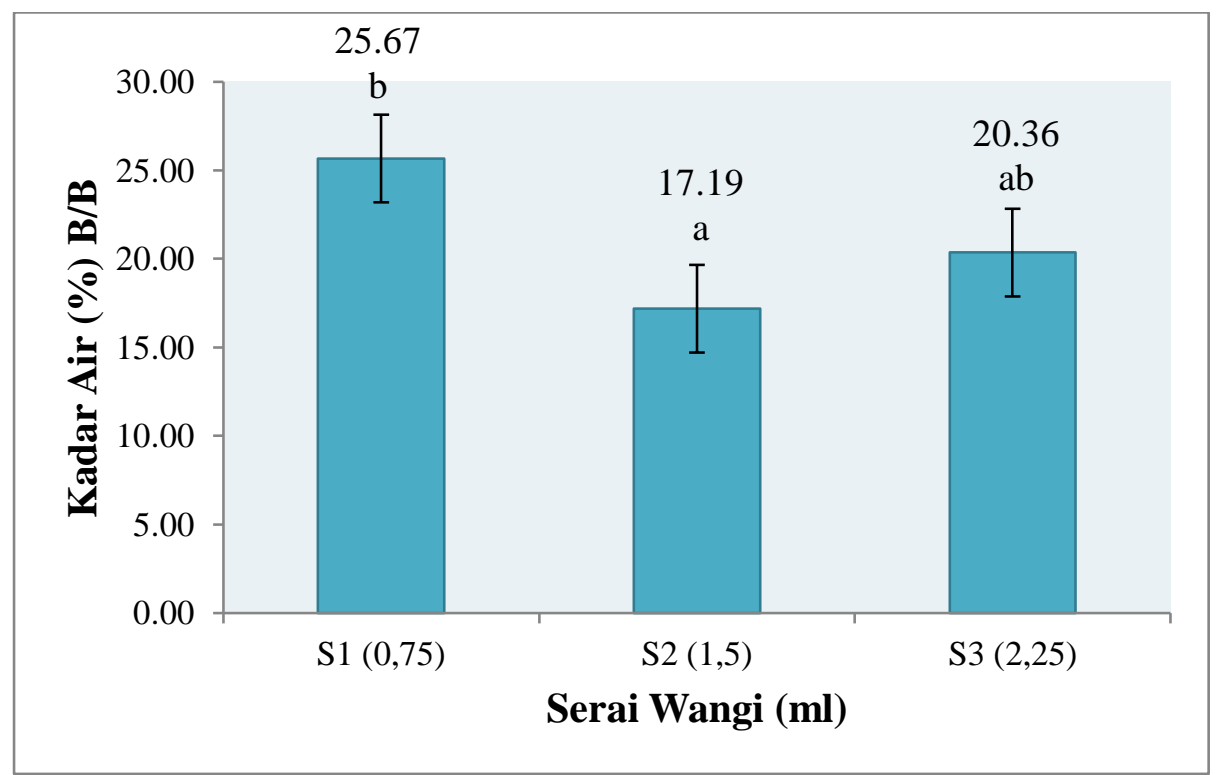

Gambar 2. Pengaruh konsentrasi serai wangi (S) terhadap nilai kadar air hard candy (nilai-nilai yang diikuti oleh huruf yang sama menunjukkan perbedaan nyata, DMRT 0,05 taraf $1=12,12$, taraf $2=12,71, \mathrm{KK}=155.902 \%$ ).

Dari Gambar 2, nilai kadar air yang terdapat pada permen keras (Hard Candy) yang dihasilkan dari penambahan serai wangi $0,75 \mathrm{ml}$ mengalami kenaikan sebanyak $25,60 \%$. Nilai kadar air yang terdapat pada penambahan serai wangi $1,5 \mathrm{ml}$ mengalami penurunan sebanyak $17,19 \%$. Sedangkan nilai kadar air yang terdapat pada penambahan $2.25 \mathrm{ml}$ mengalami kenaikan kembali yaitu sebanyak 20,36\%. Hal ini diduga karena kemampuan serai wangi sedikit larut dalam air, sehingga menyebabkan kadar air yang diperoleh memiliki nilai yang tidak konstan ataupun seimbang dan mengalami kejanggalan. Menurut SNI 3547.1:2008 (2008) menyatakan bahwa kembang gula keras, kadar air maksimal 3,5\% maka kadar air dari permen keras (Hard Candy) tidak memenuhi syarat mutu. Hasil penelitian menunjukkan bahwa, semakin sedikit serai wangi yang digunakan maka akan menghasilkan kadar air yang tinggi dan begitu juga sebaliknya karena pada saat pemasakan tidak menggunakan waktu yang lama sehingga terkandung air yang lebih tinggi, sehingga masih tertinggal pada permen keras (Hard Candy) dengan serai wangi yang paling rendah.

Pengaruh Konsentrasi Minyak Serai Wangi (Cymbopogon nardus L.) dan Sari Buah Jeruk Nipis (Citrus aurantifolia Swingle) terhadap Sifat Kimia dan Sensori Permen Keras (Hard Candy) (Maya Maulida Zamda, Anshar Patria, Ismail Sulaiman)

Jurnal Ilmiah Mahasiswa Pertanian, Vol. 4, No. 4, November 2019: 337-344 


\section{Gula Reduksi}

Nilai kadar gula reduksi yang didapatkan sesuai dengan syarat mutu kembang gula lunak yang disyaratkan SNI yaitu maksimal 20.0\%. Hasil sidik ragam menunjukkan bahwa, konsentrasi jeruk nipis berpengaruh nyata $(\mathrm{P}<0,05)$ terhadap kadar gula reduksi yang diperoleh. Pengaruh konsentrasi jeruk nipis yang ditambahkan terhadap kadar gula reduksi hard candy dapat dilihat pada Gambar 3.

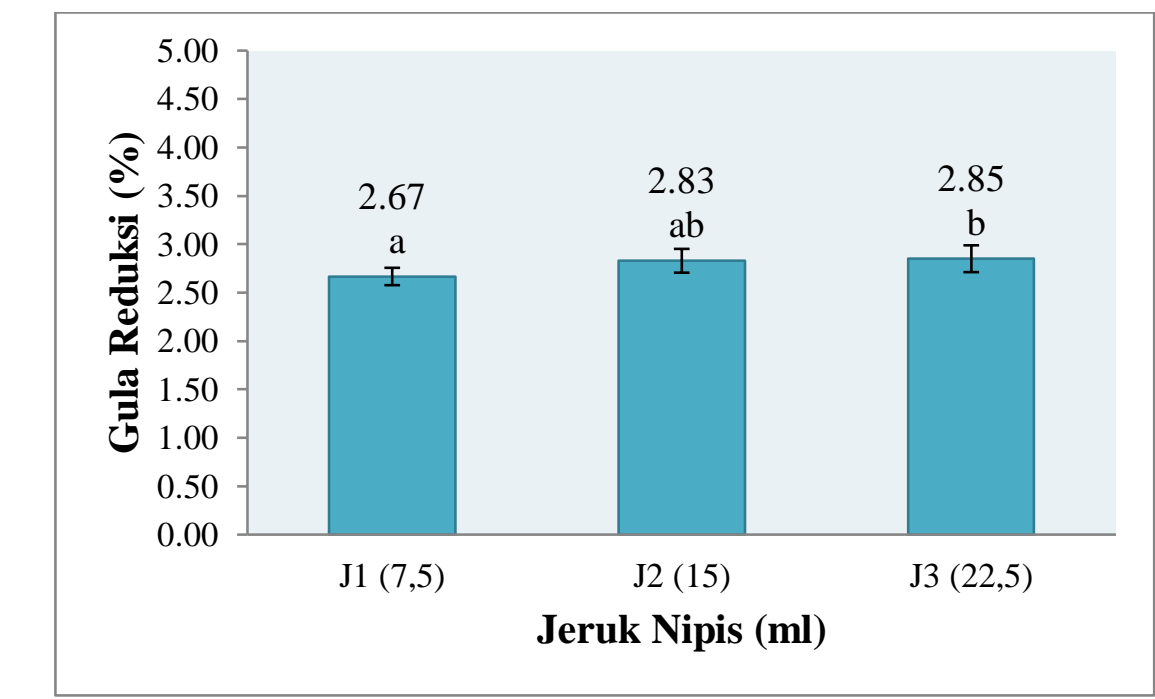

Gambar 3. Pengaruh konsentrasi jeruk nipis terhadap kadar gula reduksi hard candy serai wangi (nilai-nilai yang diikuti oleh huruf yang sama menunjukkan perbedaan nyata, $\mathrm{DMRT}_{0,01}$ taraf $1=0,15$, taraf $2=0,16, \mathrm{KK}=9,48 \%$ ).

Berdasarkan Gambar 3, hasil uji DMRT konsentrasi jeruk nipis 22,5 ml yang digunakan menghasilkan kadar gula reduksi hard candy tertinggi yaitu 2,85\%, sedangkan kadar gula reduksi hard candy terendah diperoleh dari konsentrasi jeruk nipis 7,5 ml yaitu dengan kadar air sebesar 2,67\%. Hal ini diduga karena semakin banyak jeruk nipis yang digunakan maka gula reduksi akan meningkat sehingga hard candy yang dihasilkan menjadi lengket. Menurut Faridah et al., (2008), gula reduksi yang terdapat dalam suatu bahan sangat menentukan karakteristik produk. Jika gula reduksi yang diperoleh tinggi maka produk yang dihasilkan cenderung lengket karena sukrosa yang digunakan rendah. Berdasarkan hasil penelitian kadar gula reduksi hard candy mengadung 2,85\% gula reduksi, berdasarkan hasil tersebut maka memenuhi spesifikasi SNI No. 01-3547-2008 yang mengandung gula reduksi maksimal 24,0\%.

\section{Dextrose Equivalent}

Dextrose equivalent yang didapatkan dari hasil analisis pada hard candy serai wangi yaitu berkisar 0,27\% - 0,31\% dengan rata 0,29\%. Nilai dextrose equivalent yang dihasilkan tersebut sesuai dengan standar SNI. 01-2593-1992 yaitu dengan kadar maksimal 20. Hasil sidik ragam

Pengaruh Konsentrasi Minyak Serai Wangi (Cymbopogon nardus L.) dan Sari Buah Jeruk Nipis (Citrus aurantifolia Swingle) terhadap Sifat Kimia dan Sensori Permen Keras (Hard Candy) (Maya Maulida Zamda, Anshar Patria, Ismail Sulaiman) 
menunjukkan bahwa, konsentrasi serai wangi dan jeruk nipis berpengaruh nyata $(\mathrm{P} \leq 0,05)$ terhadap dextrose equivalent yang diperoleh. Pengaruh konsentrasi serai wangi dan jeruk nipis pada hard candy dapat dilihat pada Gambar 4.

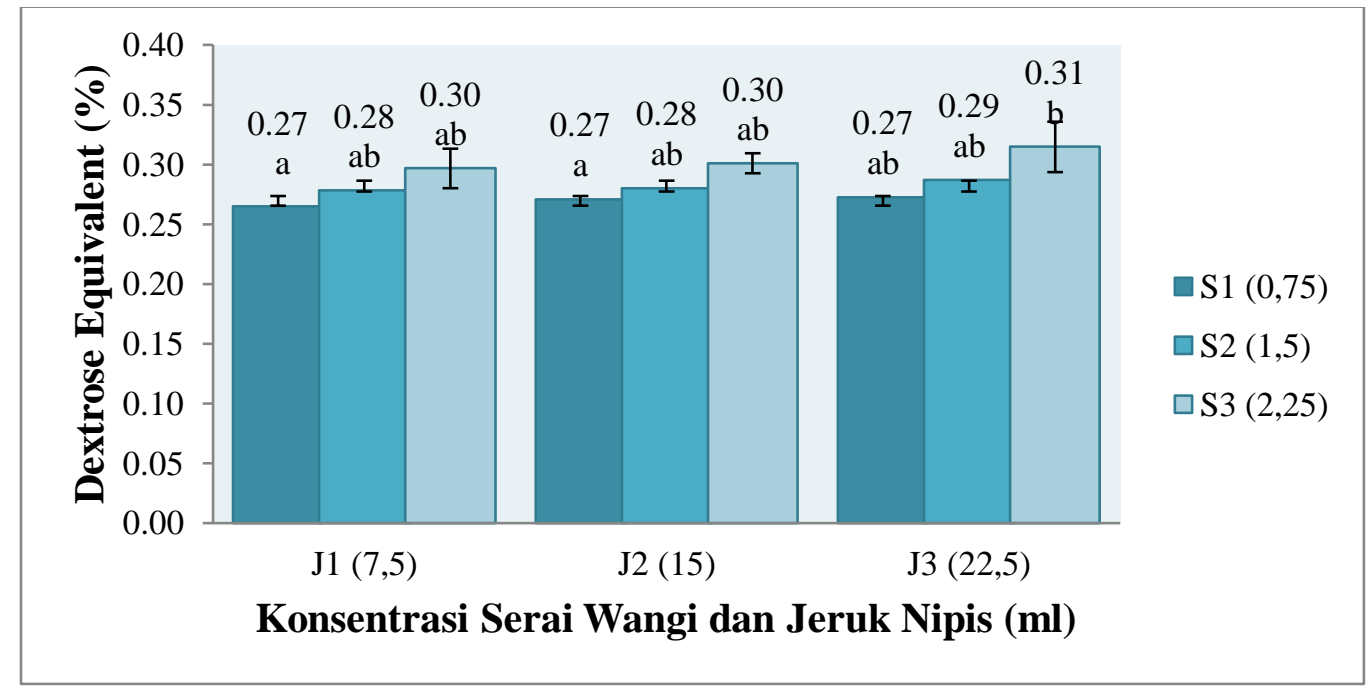

Gambar 4. Interaksi antara konsentrasi serai wangi (S) dan jeruk nipis (J) terhadap dextrose equivalent hard candy serai wangi (nilai yang dikuti oleh huruf yang sama tidak menunjukkan perbedaan yang nyata, DMRT 0.05 taraf $1=0,032$, taraf $2=0,033$, taraf $3=0,034$, taraf $4=0,035$, taraf $5=0,035$, taraf $6=0,036$, taraf $7=0,036$, taraf $8=0,036, \mathrm{KK}=3.50 \%$ ).

Berdasarkan Gambar 4 menunjukkan bahwa interaksi konsentrasi serai wangi dan jeruk nipis mempengaruhi tingkat dextrose equivalent permen keras (Hard Candy). Semakin tinggi kosentrasi serai wangi dan jeruk nipis yang digunakan maka dextrose equivalent pada permen keras (Hard Candy) yang dihasilkan semakin meningkat karena persentase setiap perlakuan berbeda konsentrasi. Hal ini diduga karena konsentrasi jeruk nipis yang digunakan lebih banyak di bandingkan konsentrasi serai wangi, sehingga dextrose equivalent pada permen keras (Hard Candy) berwarna merah kecoklatan. Sedangkan jika konsentrasi serai wangi lebih banyak dibandingkan konsentrasi jeruk nipis maka dextrose equivalent pada permen keras (Hard Candy) menghasilkan merah muda keungungan. Oleh karena itu, nilai dextrose equivalent antar setiap perlakuan tidak jauh berbeda sehingga menghasilkan dextrose equivalent pada permen keras (Hard Candy). Menurut Zulkarnain (2014) semakin tinggi suhu maka semakin cepat pula jalannya reaksi berwarna merah kecoklatan. Pada suhu yang sama, dextrose yang terbentuk pada konsentrasi rendah lebih banyak menghasilkan merah muda keungungan dari pada konsentrasi tinggi banyak menghasilkan merah kecoklatan.

Pengaruh Konsentrasi Minyak Serai Wangi (Cymbopogon nardus L.) dan Sari Buah Jeruk Nipis (Citrus aurantifolia Swingle) terhadap Sifat Kimia dan Sensori Permen Keras (Hard Candy) (Maya Maulida Zamda, Anshar Patria, Ismail Sulaiman)

Jurnal Ilmiah Mahasiswa Pertanian, Vol. 4, No. 4, November 2019: 337-344 


\section{KESIMPULAN DAN SARAN}

Secara umum menurut kadar air dengan konsentrasi 22,5 ml memberikan hasil tertinggi untuk jeruk nipis dengan nilai adalah 24,85\% sedangkan kadar air dengan konsentrasi $0,75 \mathrm{ml}$ memberikan hasil tertinggi untuk serai wangi dengan nilai $25,67 \%$ dan gula reduksi yang tinggi diperoleh berdasarkan konsentrasi jeruk nipis (J3) 22,5 ml dan gula reduksi terendah diperoleh berdasarkan konsentrasi jeruk nipis (J1) 7,5 ml. Sedangkan dextrose equivalent interaksi antara konsentrasi serai wangi dan jeruk nipis hanya berpengaruh nyata dengan nilai $(\mathrm{P} \geq 0,05)$.

Perlu dilakukan penelitian lanjutan dengan kombinasi serai wangi dan jeruk nipis agar menghasilkan hard candy dengan karakteristik yang lebih baik dari sebelumnya dan lakukan pembuatan cetakan permen dan alat pembungkus agar lebih disukai oleh panelis. Kemudian menghasilkan hard candy dengan tekstur yang tidak mudah lengket.

\section{DAFTAR PUSTAKA}

Andarwulan, N, Kusnandar, F, Herawati, D. 2011. Analisis Pangan. Dian Rakyat, Jakarta.

Astuti, Erna. 2012. Pemisahan Sitral dari Minyak Atsiri Serai Dapur (Cymbopogon citrates) sebagai Pelangsing Aromaterapi. Jurnal Fakultas Matematika dan Ilmu Pengetahuan Alam. Institut Pertanian Bogor, Bogor.

BSN (Badan Standarisasi Nasional). 2010. SNI 3140.3:2010. Gula Kristal. Badan Standarisasi Nasional, Jakarta.

BSN (Badan Standardisasi Nasional). 1994. SNI 01-3544-1994. Sirup Glukosa. Badan Standardisasi Nasional, Jakarta.

BSN (Badan Standardisasi Nasional). 1994. SNI 01-3553-1994. Air. Badan Starisasi Nasional, Jakarta.

Buckle, K. A., Edwards, R. A., Fleet, G. H., and otton, M. 1987. Ilmu pangan. Penerjemah Hari Purnomo dan Adiono. Universitas Indonesia Press, Jakarta.

Dedi, I, dan Alamsyah. 2017. Kondisi Sosial Ekonomi Masyarakat Petani Serai Wangi (Cymbopogon Nardus L). Studi di Gampong Kecamatan Terangun Kabupaten Gayo

Lues. Jurnal Ilmiah Mahasiswa FISIP Universitas Syiah Kuala 2(2): 944-965.

Faridah A, Pada KS, Yulastri A, dan Yusuf L. 2008. Patiseri Jilid 3. Departemen Pendidikan Nasional, Jakarta.

Haryati, A. 2004. Produksi Maltodekstrin Dari Pati Umbi Minor Secara Enzimatis. Skripsi Teknologi Industri Pertanian. Fakultas Teknologi Pertanian. Institut Pertanian Bogor, Bogor.

Kurniawati, N. 2010. Sehat Dan Cantik Alami Berkat Khasiat Bumbu Dapur. Mizan Pustaka, Bandung.

Sarwono B. 2001. Khasiat Dan Manfaat Jeruk Nipis. Agromedia Pustaka, Jakarta.

United States Departement Of Agriculture 2001. http://www.nutritiondata.com/facts/fruitsand-fruit-juices/1936/2. Diakses 17 Agustus 2018.

Zulkarnain. 2014. Dasar-Dasar hotikultura. Bumi Aksar, Jakarta.

Pengaruh Konsentrasi Minyak Serai Wangi (Cymbopogon nardus L.) dan Sari Buah Jeruk Nipis (Citrus aurantifolia Swingle) terhadap Sifat Kimia dan Sensori Permen Keras (Hard Candy) (Maya Maulida Zamda, Anshar Patria, Ismail Sulaiman)

Jurnal Ilmiah Mahasiswa Pertanian, Vol. 4, No. 4, November 2019: 337-344 